\title{
Structural Response of Offshore Plants to Risk-Based Blast Load
}

\author{
YeongAe Heo \\ Samsung Heavy Industries, Geoje, Korea
}

http://dx.doi.org/10.5659/AIKAR.2013.15.3.151

\begin{abstract}
Offshore oil and gas process plants are exposed to hazardous accidents such as explosion and fire, so that the structural components should resist such accidental loads. Given the possibilities of thousands of different scenarios for the occurrence of an accidental hazard, the best way to predict a reasonable size of a specific accidental load would be the employment of a probabilistic approach. Having the fact that a specific procedure for probabilistic accidental hazard analysis has not yet been established especially for explosion and fire hazards, it is widely accepted that engineers usually take simple and conservative figures in assuming uncertainties inherent in the procedure, resulting either in underestimation or more likely in overestimation in the topside structural design for offshore plants. The variation in the results of a probabilistic approach is determined by the assumptions accepted in the procedures of explosion probability computation, explosion analysis, and structural analysis. A design overpressure load for a sample offshore plant is determined according to the proposed probabilistic approach in this study. CFD analysis results using a Flame Acceleration Simulator, FLACS_v9.1, are utilized to create an overpressure hazard curve. Moreover, the negative impulse and frequency contents of a blast wave are considerably influencing structural responses, but those are completely ignored in a widely used triangular form of blast wave. An idealistic blast wave profile deploying both negative and positive pulses is proposed in this study. A topside process module and piperack with blast wall are 3D FE modeled for structural analysis using LS-DYNA. Three different types of blast wave profiles are applied, two of typical triangular forms having different impulse and the proposed load profile. In conclusion, it is found that a typical triangular blast load leads to overestimation in structural design.
\end{abstract}

Keywords: Dispersion, Explosion, Risk Analysis, Offshore Plants, Hydrocarbon Gas, Probabilistic Approach

\section{INTRODUCTION}

In offshore oil and gas industries, accidents have generally led to catastrophic losses in terms of human lives, economy, and environment as we have seen from the historical offshore disasters such as 1980 Alexander Kielland capsize and 1988 Piper Alpha explosion until the recent BP Deepwater Horizon disaster in 2011. Since 1980, international rules and regulations have been strengthened by Norwegian Petroleum Safety Authority and the UK Health and Safety Executive (HSE) focusing on implementation of a probabilistic quantitative risk assessment (QRA) which includes the entire risk studies for all possible hazards on each offshore project such as explosion, fire, cold spill, dropped object, collision, corrosion and etc.

Explosion induced by hydrocarbon gas leak is the most hazardous accidental events on the topside of offshore plants along

\footnotetext{
Corresponding Author : YeongAe Heo, Senior Researcher

Samsung Heavy Industries, Geoje, Korea

Tel : +82-10-6312-2558 e-mail : yaheo@ucdavis.edu
}

The author would like to acknowledge the colleagues at Samsung Heavy Industries for their assistance on the project.

This is an Open Access article distributed under the terms of the Creative Commons Attribution Non-Commercial License (http://creativecommons. org/licenses/by-nc/3.0/) which permits unrestricted non-commercial use, distribution, and reproduction in any medium, provided the original work is properly cited. with fire. Hence, it is required to meet the performance criteria of design offshore safety critical elements subjected to a specific level of risk-based explosion load by international standards (BS EN ISO 17776, 2002 and ISO/FDIS 19901-3, 2010). Although probabilistic approaches are commonly applied in offshore and shipbuilding industries in order to identify such an accidental load, a concrete guideline, however, has not been established yet. Hence, there is large variability in assessing the safety of offshore plants according to the current guidelines, which depends on assumptions of uncertainties resided in the following analysis steps: 1) the details of explosion scenario relevant parameters used in data analysis for computing the annual probability of exceeding a specific level of explosion loads, so called, explosion hazard analysis, 2) the explosion load profile for nonlinear dynamic finite element (NDFE) structural analysis. Such assumptions lead to mainly overestimation as well as insufficient safety for structural design.

For probabilistic explosion risk assessment, firstly it is essential to identify hazardous inventories from which hydrocarbon gas is possibly released. Since control valves and isolation valves are automatically closed by the ESD(Emergency Shutdown) or PSD(Process Shutdown) signal, when a leakage takes place on a topside process system during the operation, the leak rate and leak duration for a specific opening size are determined by the inventory size, the stream properties, and hydrocarbon gas composition entrapped within the isolatable sections. It is assumed that an isolatable section is assigned to a leak scenario comprised of a specific hole size, leak location, inventory size, and stream properties. Leak frequency of each isolatable inventory is calculated 
by summation of release rates for piping per meter and each vessel based on hydrocarbon release database (Hydrocarbon Releases System, 1992 2012). Since leak scenario parameters and leak frequencies highly depends on topside process design information, the results will differ noticeably at each design stage if there is big design change or general estimation is used.

Secondly, the leak scenarios can be extended into explosion scenarios considering leak direction, wind speed, wind direction, ignition location, and ignition time. Annual rate of occurrence for $i^{\text {th }}$ explosion scenario ( $P_{E}^{i}$ ) is computed by the product of the probability of each scenario parameters and hydrocarbon gas leak frequency $\left(\lambda_{L}^{i}\right)$ for $\boldsymbol{i}^{\text {th }}$ isolatable section shown in (1).

$$
P_{E}^{i}=\lambda_{L}^{i} \cdot P_{H}^{i} \cdot P_{L L}^{i} \cdot P_{L D}^{i} \cdot P_{W S}^{i} \cdot P_{W D}^{i} \cdot P_{I L}^{i} \cdot P_{I T}^{i} \cdot P_{I}^{i}
$$

where $P_{H}^{i}, P_{L L}^{i}, P_{L D}^{i}, P_{W S}^{i}, P_{W D}^{i}, P_{I L}^{i}, P_{I T}^{i}, P_{I}^{i}$ are probability of hole size, leak location, leak direction, wind speed, wind direction, ignition location, ignition time, and ignition of FPSO's for $i^{\text {th }}$ explosion scenario respectively. Annual rate of occurrence for each explosion scenario will change depending on the probability density function and the interval length of each scenario parameter.

In sequence, corresponding explosion responses such as overpressures, drag pressures, and impulses to each explosion scenario are necessary to be generated by 3D CFD simulations. An explosion analysis should be performed subsequent to dispersion analysis in order to use flammable gas cloud profile for a leak scenario with a specific wind condition. Most of engineers in offshore plant industries, however, blindly use box-shaped stoichiometric volume suggested by Norsok Standard Z-013 (2010) instead of real gas cloud generated by dispersion analysis with being unaware that the explosion responses using the stoichiometric gas cloud considerably vary depending on the location, shape, and the concentration ratio of hydrocarbon gas mixture, not only because dispersion analysis code hadn't been integrated within any explosion analysis software until 2000's, but also it is fairly expensive in terms of computational time. The procedure of an advanced explosion risk analysis is proposed with limited number of simulations in this study which will also be a point of comparison with high number of simulations as best prediction in future study.

Finally, a structural design can be assessed by an design explosion load obtained from plotting annual rate of exceedance versus explosion response, so called hazard curve. Nonlinear and dynamic effect should be considered during the structural analysis subjected to the computed design load for accidental loads such as explosion, fire, drop impact, and so on (BS EN ISO 199011, 2005 and BS EN ISO 19902, 2007). Hence, triangular form of blast load characterized by design pressure $\left(P_{\max }\right)$ and duration (UKOOA, 2003) is adopted in general. However, such a dynamic load is not appropriate to estimate structural response because it doesn't account for the frequency contents and negative pressure, which are observed in most case of explosion simulation responses using a dispersed gas cloud on the topside of offshore plants. Also, such non-stationary characteristics of a explosion response curve strongly affect structural responses. 3D NDFE structural analyses during three different blast load cases are carried out using an advanced transient finite element simulation software package,
LS-DYNA, to examine structural response sensitivity to the nonstationary characteristics of blast loads for a topside module in this study.

\section{EXPLOSION HAZARD ANALYSIS}

\subsection{Leak Frequency: $\lambda_{L}$}

For leak frequency calculation, piping length, the number of equipments, valves, and flanges within each isolatable section are necessary. Figure 1 depicts an isolatable section enclosed by control valves marked with pink. All the values are measured according to PFD (Process Flow Diagram) and P\&ID (Piping and Instrument Diagram) based on the Hydrocarbon Releases System (1992 2012).

\subsection{Leak Scenario Parameters: $P_{H}, P_{L L}, P_{L D}$}

A leak scenario is composed of:

- Hole size (mm)

- Leak location

- Leak direction

For a specific hole size, leak rate $(Q)$ and leak duration $\left(t_{L d}\right)$ are evaluated by isolatable section volume, pressure, temperature, and mole fraction of the stream within the section. Similar observation is demonstrated for isolatable section volumes in Table 2. Unlike leak location and leak direction applying equal probability density, for the probability density of hole size, Hydrocarbon Releases System (1992 2012) provides hole size distribution for individual equipments. Leak rates for a specific hole size are computed for each section by IP Research Report (2006) based on stream information such as pressure, temperature, and mole fraction provided by a chemical process simulator, Aspen HYSYS.

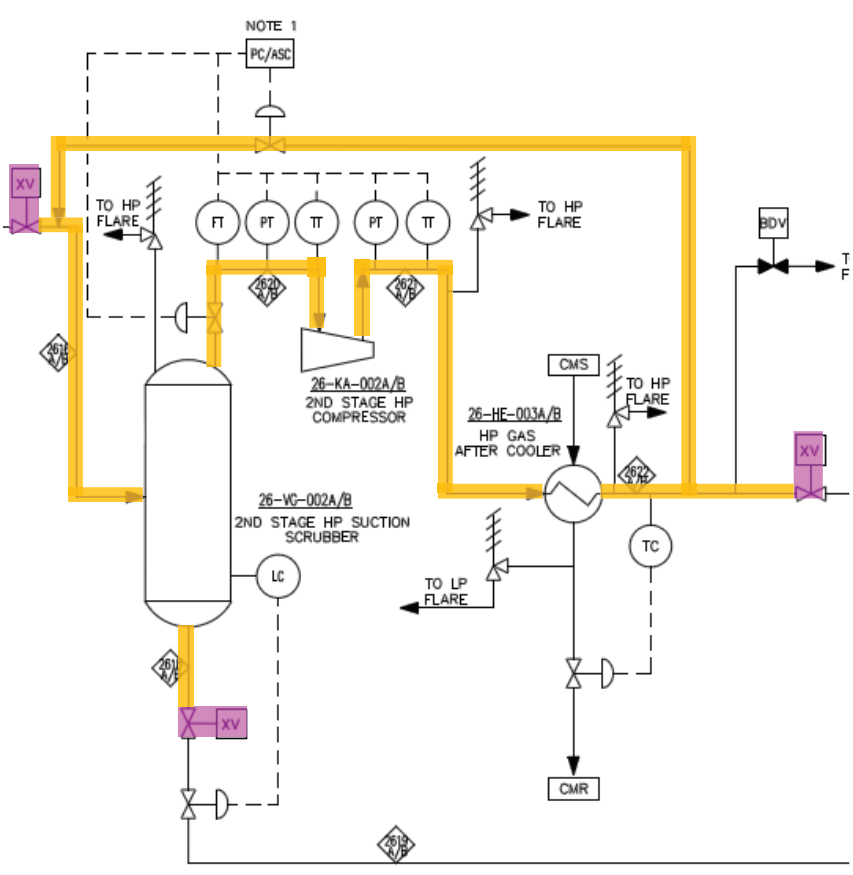

Figure 1. PFD diagram for a sample isolatable section 
Table 1. Example of leak frequencies

\begin{tabular}{c|c}
\hline Section No. & Proposed \\
\hline 3 & $1.41 \mathrm{E}-02$ \\
\hline 4 & $1.34 . \mathrm{E}-02$ \\
\hline 5 & $4.91 . \mathrm{E}-02$ \\
\hline 6 & $8.53 \cdot \mathrm{E}-02$ \\
\hline 7 & $4.37 . \mathrm{E}-02$ \\
\hline 8 & $1.03 . \mathrm{E}-01$ \\
\hline 9 & $1.35 . \mathrm{E}-02$ \\
\hline 10 & $6.37 . \mathrm{E}-02$ \\
\hline 11 & $2.81 . \mathrm{E}-02$ \\
\hline 18 & $9.93 . \mathrm{E}-02$ \\
\hline 19 & $5.36 . \mathrm{E}-02$ \\
\hline 20 & $2.95 . \mathrm{E}-02$ \\
\hline
\end{tabular}

Table 2. Example of isolatable section volumes $\left(\mathrm{m}^{3}\right)$

\begin{tabular}{c|c}
\hline Section No. & Volume \\
\hline 3 & 5 \\
\hline 4 & 21 \\
\hline 5 & 101 \\
\hline 6 & 143 \\
\hline 7 & 2 \\
\hline 8 & 11 \\
\hline 9 & 18 \\
\hline 10 & 17 \\
\hline 11 & 5 \\
\hline 18 & 9 \\
\hline 19 & 142 \\
\hline 20 & 69 \\
\hline
\end{tabular}

$$
\begin{gathered}
Q=Q_{0} \exp \left[\frac{-Q_{0}}{m_{G}} t\right] \\
Q_{0}=C_{D} A P_{0} Z
\end{gathered}
$$

$$
Z=\sqrt{\frac{M \gamma}{R T_{0}}\left(\frac{2}{\gamma+1}\right)^{\frac{\gamma+1}{\gamma-1}}}
$$

where $Q_{0}$ denotes initial leak rate, $m_{G}$ denotes mass of gas, $C_{D}$ denotes discharge coefficient, A denotes hole area $\left(\mathrm{m}^{2}\right), P_{0}$ denotes initial pressure $\left(\mathrm{N} / \mathrm{m}^{2}\right), M$ denotes molecular weight of gas, $\gamma$ denotes specific heat ratio, $R$ denotes universal gas constant, $T_{0}$ denotes initial temperature. Sample stream information and the computed leak rate with regards to the hole size of $150 \mathrm{~mm}$ for section 5 and 11 are shown in Table 3 and Figure 2. Since hole size, section volume, stream properties, and hydrocarbon gas composition are directly linked to leak rate and duration, it is one of the reasons for unreasonable prediction in probabilistic explosion risk assessment.

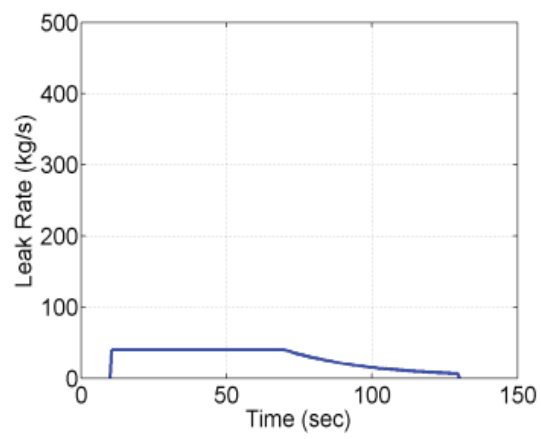

(a) Section 5

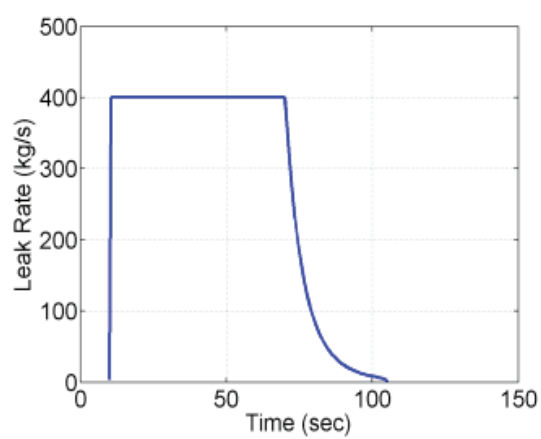

(b) Section 11

Figure 2. Leak rate.

Table 3. Stream information of isolatable section 5 and section 11 .

\begin{tabular}{l|c|c}
\hline Section No. & Section 5 & Section 11 \\
\hline Temperature $\left(\mathrm{C}^{\circ}\right)$ & 109 & 140 \\
\hline Pressure $(\mathrm{bar})$ & 12.5 & 145 \\
\hline Mass Density $\left(\mathrm{kg} / \mathrm{m}^{3}\right)$ & 14.9 & 141.7 \\
\hline Methane & 0.3134 & 0.5248 \\
\hline Ethane & 0.1311 & 0.1636 \\
\hline Propane & 0.1943 & 0.1726 \\
\hline i-Butane & 0.0382 & 0.0210 \\
\hline $\mathrm{n}$-Butane & 0.0796 & 0.0344 \\
\hline i-Pentane & 0.0218 & 0.0043 \\
\hline $\mathrm{n}$-Pentane & 0.0250 & 0.0037 \\
\hline C6 ${ }^{*}$ & 0.0188 & 0.0006 \\
\hline C7 $^{*}$ & 0.0191 & 0 \\
\hline
\end{tabular}

All possible leak locations and leak directions should be thoroughly investigated for the best prediction. However, limited leak locations and leak directions are considered in this study because the main purpose of this study is to show the effect of characteristic of probabilistic risk-based blast load on structural reasponse rather than to find out the precise overpressure response. 
Hence, two leak locations are considered at the center of specific modules such as seperation module and the 2 nd stage HP compression module, and two leak directions are considered along $\pm x$ direction in this study.

\subsection{Wind Scenario Parameters: $\boldsymbol{P}_{W S}, \boldsymbol{P}_{W D}$}

As for the probability density of wind scenario parameters is identified through metocean analysis and heading analysis based on the environmental conditions at a specific oil and gas field and the weathervanning performance of an offshore plant respectively. In this study it is assumed that the weathervanning angle is $15^{\circ}$ with respect to the return period of 100 years for wind, waves, and current. Accordingly, two wind directions, $0^{\circ}$ and $15^{\circ}$ are considered. For wind speed, it is also assumed that $2.5 \mathrm{~m} / \mathrm{s}, 7.5 \mathrm{~m} / \mathrm{s}$, $12.5 \mathrm{~m} / \mathrm{s}$ reasonably represents low, medium, and high wind speed based on the metocean analysis report which is offered by the owner of the oil field.

\subsection{Ignition Scenario Parameters: $\boldsymbol{P}_{I L}, \boldsymbol{P}_{I T}$}

There are two approaches to perform explosion analysis. One approach is directly to ignite a gas cloud stopping dispersion analysis at specific leak duration. The other approach is to employ a box-shaped stoichiometric gas cloud equivalent to a simulated gas cloud. This study proposes direct explosion method using a simulated gas cloud by dispersion analysis. In this case, a flammable gas cloud size increases until it reaches the max and decrease as plotted in Figure 3 due to change in leak rate and wind conditions during the dispersion analysis. Therefore, ignition time is also one of considerable random variables as well as ignition location in this study. Two of ignition time are considered, one $\left(t_{1}\right)$ when the flammable gas cloud volume reaches the max and the other $\left(t_{2}\right.$ or $\left.t_{3}\right)$ when the flammable gas cloud size becomes $60 \%$ of the max size. In this study, $t_{2}$ is selected instead of $t_{3}$ to save dispersion simulation time.

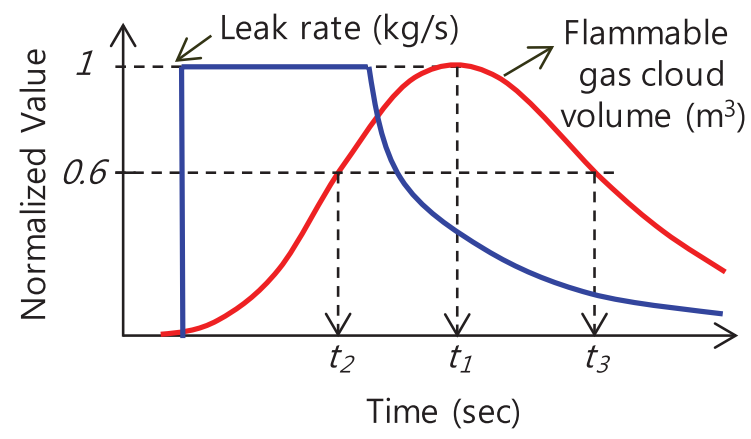

Figure 3. Normalized leak rate and flammable gas cloud volume.

For ignition location, because flammable gas concentration around an ignition point also affects explosion response, two explosion simulations using different ignition locations are carried out with respect to a simulated gas cloud at $t_{1}$ and $t_{2}$, one within upper flammable limit zone (UFL: richest flammable mixture. 13 14\%) and the other within lower flammable limit zone (LFL: smallest fraction of combustible gas. 3 4\%) as displayed in Figure 4. Uniform probability density is applied to both ignition location and ignition time.

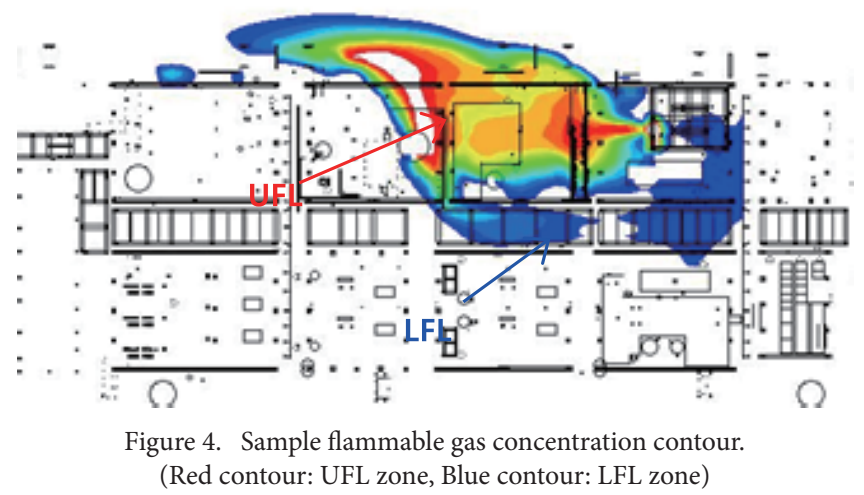

\subsection{Ignition Probability for FPSO: $P_{I}$}

Although ignition probability of flammable leak from the topside process system of offshore plants is essential in assessing explosion hazard and risk, it is not simply attainable for an individual or company to develop such a probabilistic model because it requires worldwide accidental data. Thus, most engineers adopt one of existing ignition probability models developed by collaboration with government agencies and research institutes in joint industry projects. UKOOA look-up correlation model for Offshore FPSO gas leak case (IP Research Report, 2006) also shown in (5) is applied in this study.

$$
\begin{aligned}
& y=10^{\left[m \cdot \log _{10}(x)+c\right]} \\
& \begin{cases}\text { if } x \leq 1, \quad \mathrm{~m}=0.73, \quad c=-2.89 \\
\text { else } \quad m=1.21, \quad c=-2.89\end{cases} \\
& x_{\text {min }}=0.001, \quad x_{\text {max }}=0.15
\end{aligned}
$$

where y denotes the ignition probability, $x$ denotes the leak $\operatorname{rate}(\mathrm{kg} / \mathrm{s}), m$ denotes the gradient of the correlation, and $c$ denotes the $y$-axis offset of the correlation.

\subsection{Explosion Hazard and Design Load Analysis}

An overpressure exceedance curves (also called by "Hazard Curve") as presented in Figure 5 are generated by the results of 64 explosion simulations using 16 simulated real gas clouds according to the direct explosion approach.

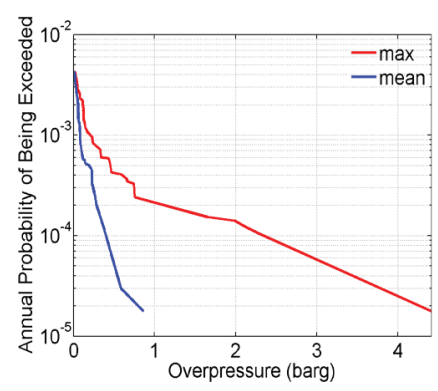

(MAX: Design pressure $=2.42$ barg; duration $=35.98 \mathrm{~ms}$ ) (MEAN: Design pressure $=0.42$ barg; duration $=94.28 \mathrm{~ms}$ ) Figure 5. Overpressure exceedance curves 
Then, a generally used triangular blast load for structural design and analysis illustrated in Figure 6 can be created by the design pressure and duration obtained from the hazard curve. In this study, the design overpressure, $P_{\max }$, is 0.4 bar and the resultant duration, $t_{d}$, is $100 \mathrm{~ms}$.

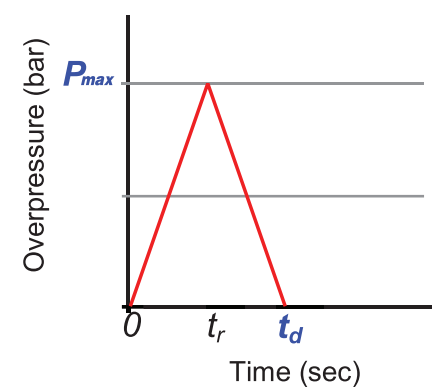

Figure 6. Typical triangular form of blast load. ( $P_{\max }$ denotes design overpressure, $t_{r}$ denotes rise time to the peak pressure, and $t_{d}$ denotes total duration of the blast load)

Such a blast wave profile shown in Figure 6 is barely observed from explosion analysis using real gas clouds formed during the dispersion simulation. Most of pressure waves oscillate between positive and negative pressure until it vanishes as shown in Figure 7, and also the intensity of negative wave is considerable.

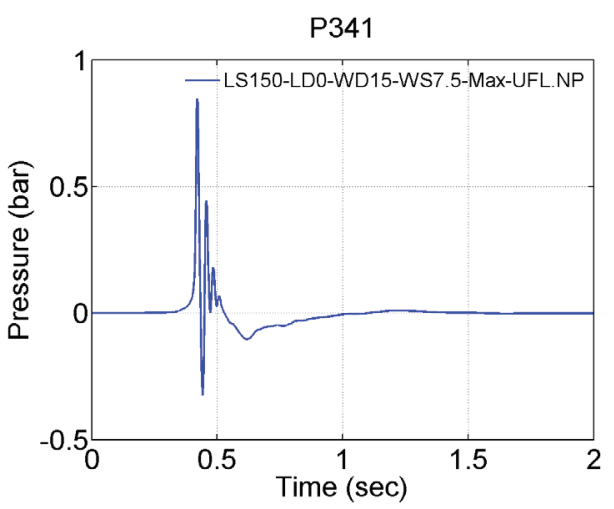

(a) measured at blast wall

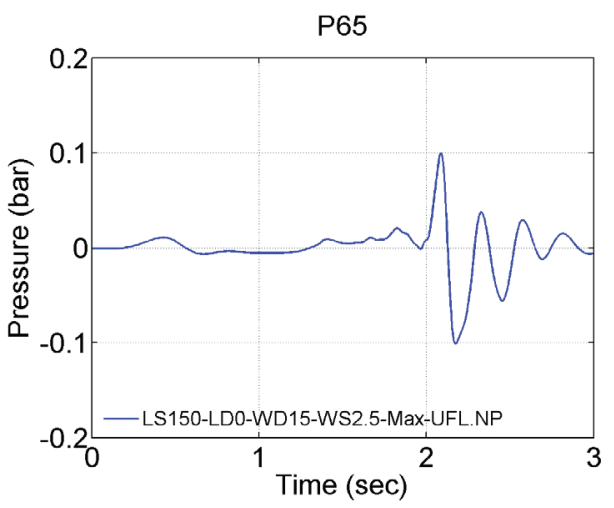

(b) measured at process deck

Figure 7. Explosion time histories recorded at a point monitor during a explosion analysis using a real gas cloud.

\section{STRUCTURAL ANALYSIS}

\subsection{Structural Details}

A sample topside process module are finite element modeled to perform 3D nonlinear dynamic structural analysis using LS-DYNA as shown in Figure 8 in order not only to investigate the effect of the nonlinear characteristics of explosion load on the structural responses but also to develop a more precise methodology to predict structural performance under explosion load. Also the dead loads from equipments on the weather deck are included in modeling.

The yield strength and ultimate strength is $355 \mathrm{MPa}$ and $490 \mathrm{MPa}$ respectively. Also, Cowper-Symonds strain rate parameters, $C$ and $p$, are set at 3200 and 5.0 respectively in this study. The natural frequencies of the system are:

- $1^{\text {st }}$ mode period : $0.353 \mathrm{sec}$

- $2^{\text {nd }}$ mode period : $0.243 \mathrm{sec}$

- $3^{\text {rd }}$ mode period : $0.170 \mathrm{sec}$

Three NDFE simulations are performed applying the three load cases listed in Table 4.

Table 4. Load cases

\begin{tabular}{l|l|l|l}
\hline & CASE1 & CASE2 & CASE3 \\
\hline Pulse type & Single pulse & Single pulse & Multiple pulses \\
\hline Peak pressure & $0.5 \mathrm{bar}$ & $0.4 \mathrm{bar}$ & $\begin{array}{l}0.4, \pm 0.2, \pm 0.1 \\
\pm 0.1\end{array}$ \\
\hline Duration & $200 \mathrm{~ms}$ & $100 \mathrm{~ms}$ & $50 \mathrm{~ms}$ for each \\
\hline Impulse & $50 \mathrm{bar} \cdot \mathrm{ms}$ & $20 \mathrm{bar} \cdot \mathrm{ms}$ & $20 \mathrm{bar} \cdot \mathrm{ms}$ \\
\hline
\end{tabular}

CASE 2 is the typical design load as described in 2.7, and CASE1 is 2.5 times greater than CASE1 in terms of impulse. Impulse is defined:

$$
I_{P}=\int P d t
$$

where $P$ denotes pressure, $I_{P}$ denotes positive pressure impulse, simply the positive area below the pressure time history. For CASE3, its impulse is equal to CASE2. However, several positive and negative pressure waves with shorter duration are applied until the total positive pressure impulse of each wave reaches the same impulse as CASE2 rather than a single pulse as CASE2. It is assumed that an exterior explosion takes place. Hence, blast pressure load is applied to the surface facing the point source of explosion towards the blast wall. 


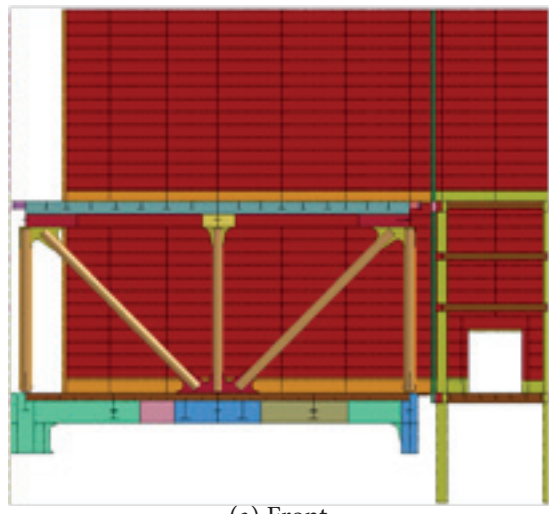

(a) Front

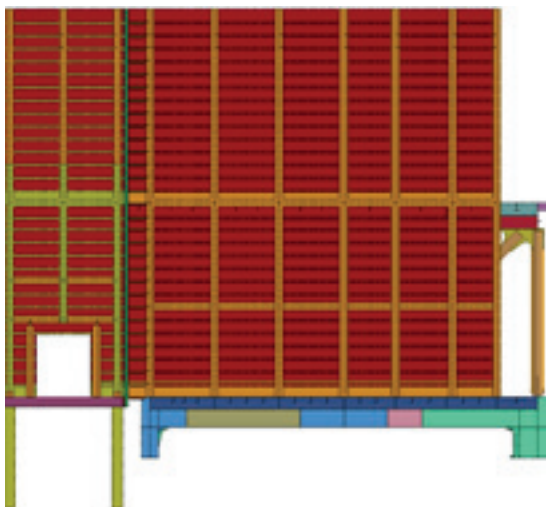

(b) Back

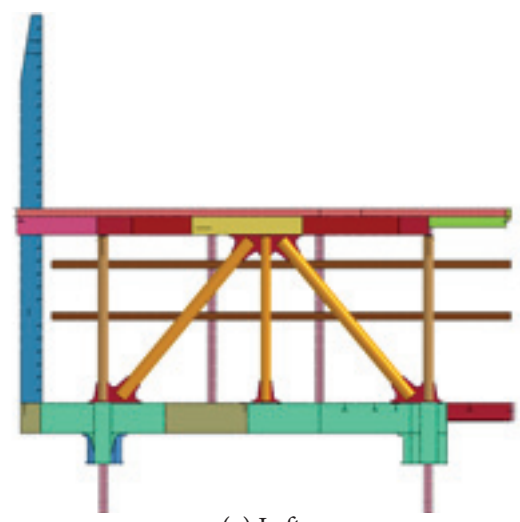

(c) Left

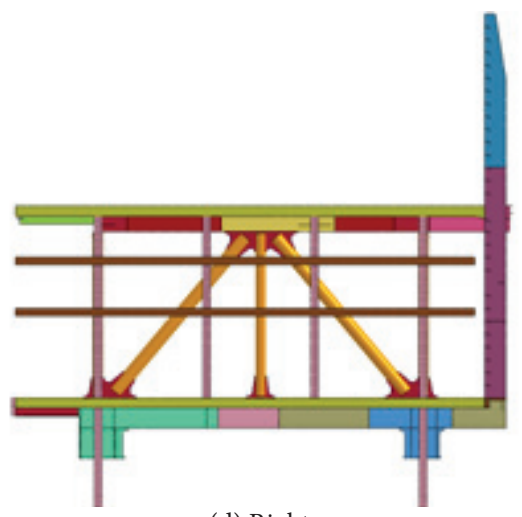

(d) Right

Figure 8. Elevation view of LS-DYNA 3D FE model for a topside process module and pipe rack with blast walls.

\subsection{Results}

The maximum strain responses of each load case plotted in Figure 9 are:

- CASE1 : $18.64 \%$

- CASE2 : $10.86 \%$

- CASE3: $7.21 \%$

Assuming that the system fails at $15 \%$ of stain, the structural system cannot resist the design explosion load for CASE1. The strain response contours are also shown in Figures 10 and 11. The upper limit of the contour is set by the yield strength. It is observed through CASE1 and CASE2 that the structure undergoes almost 1.7 times bigger damage when the structure is subjected to 2.5 times greater blast load in terms of impulse in a single triangular form. Although CASE2 and CASE3 have same impulse, CASE3 which represents a more realistic blast load having negative waves following a positive pressure wave causes about 1.5 times less damage on the structural system than CASE2. This is because the duration of blast wave is much shorter than the natural period of the structural system so the structural system does not fully respond to the first peak pressure wave due to the subsequent smaller impulses. Depending on the natural periods of a structural system and the intensity and the frequency of the subsequent pressure waves, it may cause different results though. Also it is learned that a design load is unreasonably overestimated due to inappropriate assumptions during the explosion probability calculation and explosion simulations. Therefore, if a structural performance is evaluated by blindly adopting the load for CASE1 or CASE2 without accounting for the non-stationary characteristics of actual explosion pressure waves, it would be too costly overestimated.

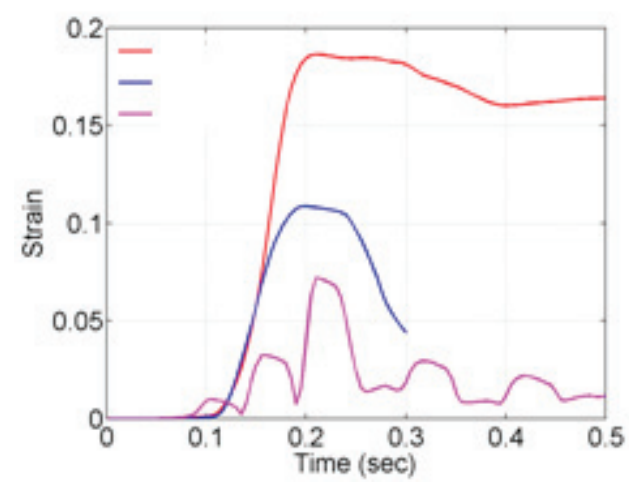

Figure 9. Maximum strain responses for three load cases

\section{CONCLUSION}

The ultimate goal of this study is to develop more reasonable methodology to evaluate structural performance during blast loading with both economy considerations and safety concerns. The procedure to estimate a design overpressure load according to a probabilistic approach is thoroughly described. It is found that the typical triangular form of design explosion load can lead to overestimation compared to the proposed design load which can 
ideally represent the real overpressure time histories deploying both positive and negative pulses. The widely adopted triangular explosion load brings more damage about 1.5 times more on the structure compared to the blast load with several positive and negative pressure waves although the amount of impulse is same for both since structural response is very sensitive to the frequency contents and the amplitude of pressure waves. Therefore, it is proposed to use a design explosion load representing the nonstationary characteristics of real pressure waves in both structural design and evaluation through this study. Further studies for practical use of the proposed design explosion load, scenario screening methodology to save analysis cost and to be more practical, correlation among random variables for explosion responses, remain for future research.

\section{REFERENCES}

British Standards Institution. (2002) Petroleum and natural gas industries-Offshore production installations-Guidelines on tools and techniques for hazard identification and risk assessment. BS EN ISO 17776.

British Standards Institution. (2005) Petroleum and natural gas industries - Specific requirements for offshore structures - Part1 : Metocean design and operating considerations. BS EN ISO 19901-1.

British Standards Institution. (2007) Petroleum and natural gas industries - Fixed steel offshore structures. BS EN ISO 19902.

Hydrocarbon Releases System. (1992 2012) Offshore Division of Health and Safety Executive. https://www.hse.gov.uk/hor3/

International Organization for Standardization. (2010) Petroleum and natural gas industries - Specific requirements for offshore structures - Part3 : Topsides structure. ISO/FDIS 19901-3.

IP Research Report. (2006). Ignition Probability Review, Model Development and Look-up Correlations. Energy Institute, London

Norsok Standard Z-013. (2010). Risk and emergency preparedness assessment. Edition 3.

UKOOA. (2003) Fire and Explosion Guidance Part 1: Avoidance and Mitigation of Explosions. Issue 1.UK Offshore Operators Association, London.

(Received April 26, 2013/Accepted September 5, 2013)

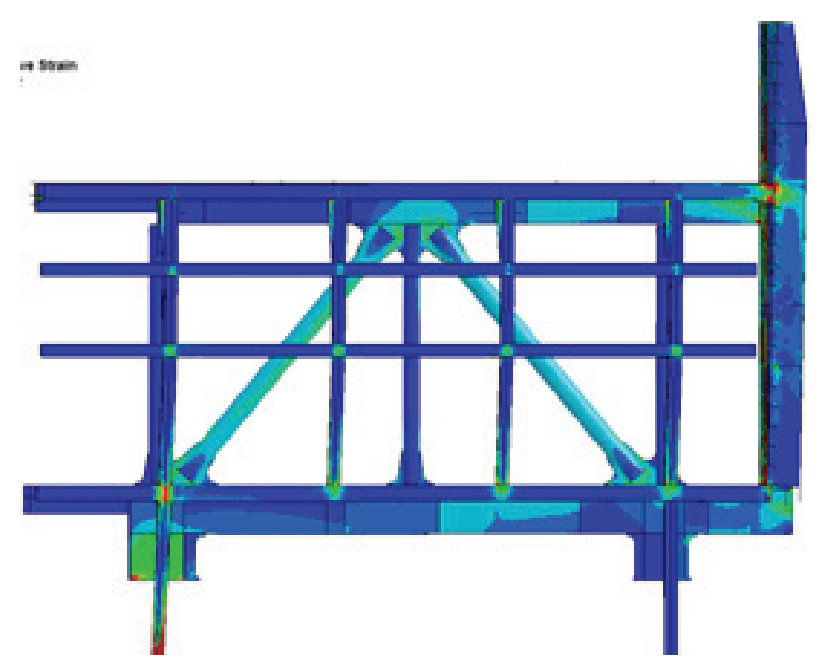

(a) CASE1-design load (max strain : 18.64\%)

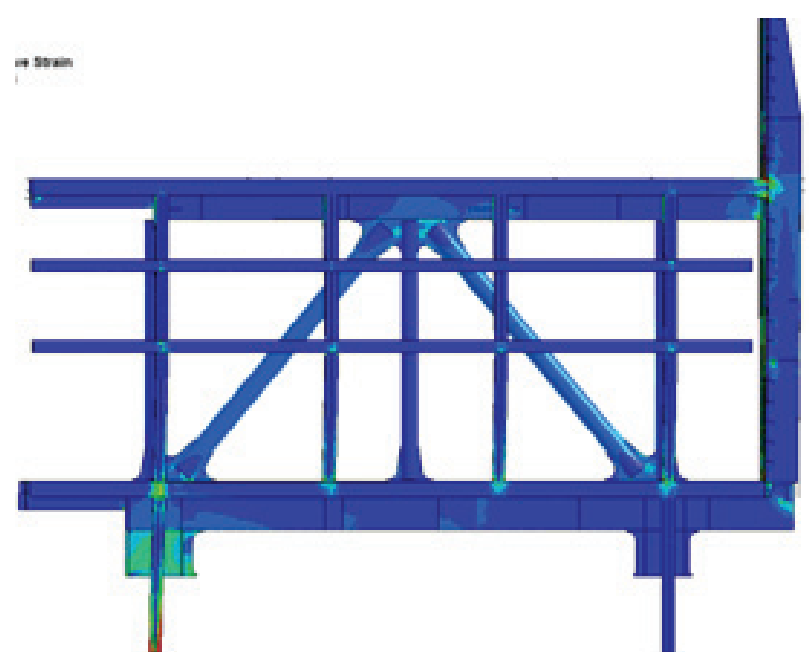

(b) CASE2-Proposed design load: Single Pulse (max strain : 10.86\%)

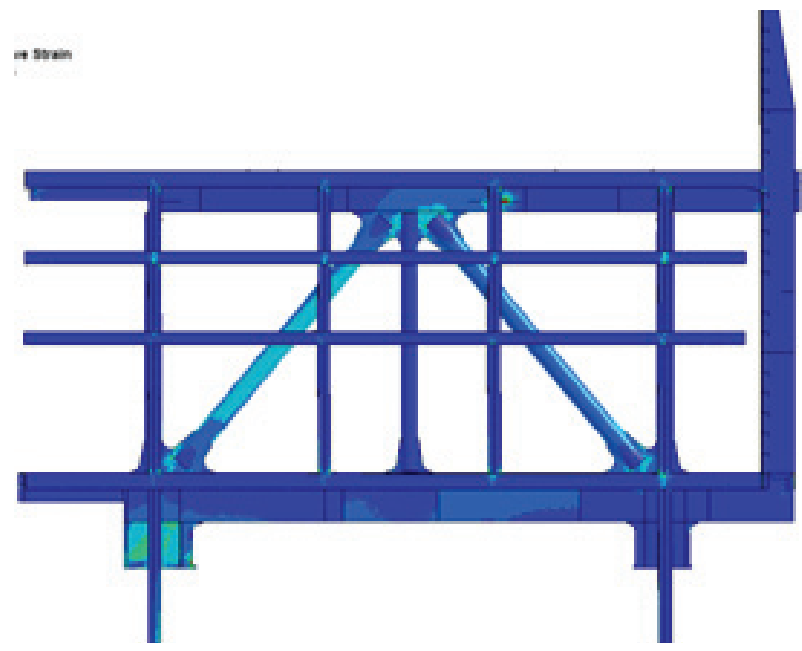

(c) CASE3-Proposed design load: Multiple Pulses (max strain : 7.21\%) Figure 10. Right side elevation view of LS-DYNA strain contours at the maximum deformation stage. 


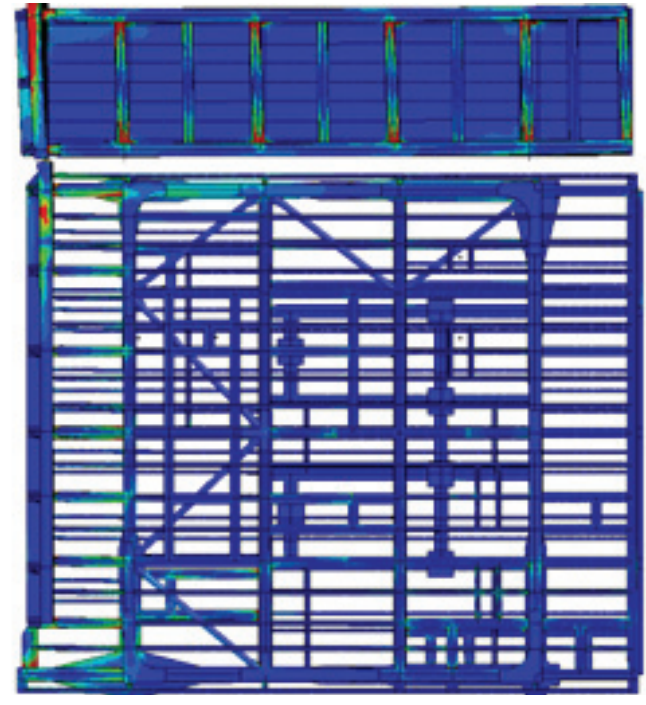

(a) CASE1-design load (max strain : 18.64\%)

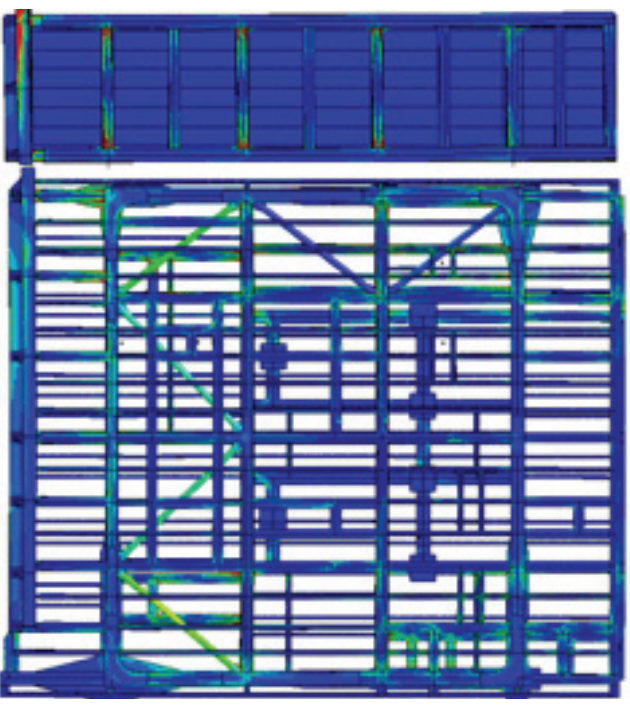

(b) CASE2-Proposed design load: Single Pulse (max strain : 10.86\%)

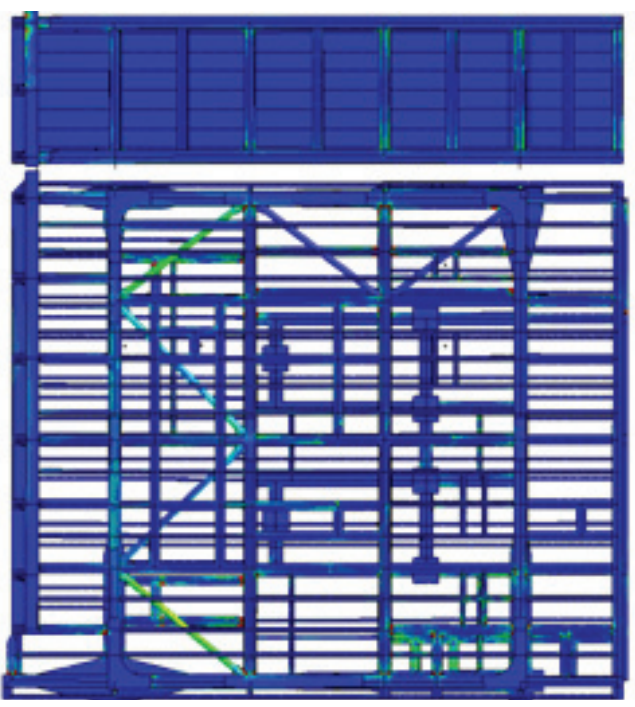

(c) CASE3-Proposed design load: Multiple Pulses (max strain : 7.21\%)

Figure 11. Plan view of LS-DYNA strain contours

$$
\text { at the maximum deformation stage }
$$

